\title{
Molecular Self-Assembling of $N$-Methylacetamide in Solvents
}

\author{
Hideyuki Minami and Makio Iwahashi \\ Department of Chemistry, School of Science, Kitasato University, 1-15-1 Kitasato, Minami-ku, Sagamihara 252-0373, Japan \\ Correspondence should be addressed to Hideyuki Minami, minami@sci.kitasato-u.ac.jp
}

Received 28 April 2011; Accepted 27 June 2011

Academic Editor: Sergio Armenta Estrela

Copyright ( $) 2011$ H. Minami and M. Iwahashi. This is an open access article distributed under the Creative Commons Attribution License, which permits unrestricted use, distribution, and reproduction in any medium, provided the original work is properly cited.

\begin{abstract}
The self-association of $\mathrm{N}$-methylacetamide (NMA), which is one of the most simple compound having a peptide bond, in various solvents such as carbon tetrachloride $\left(\mathrm{CCl}_{4}\right)$, chloroform, dichloromethane, and acetonitrile was studied through the near-infrared (NIR) spectroscopic observation at various temperatures and concentrations. An analysis assuming a successive association processes for the NMA molecules was applied to the sharp 1470-nm band (the first-overtone band of NH stretching vibration mode attributed to free NH group of NMA monomer and partly to the free, terminal NH group of NMA aggregate); the mean association number for $\mathrm{NMA}$ in $\mathrm{CCl}_{4}$ increases with increasing concentration and decreases with increasing temperature. Comparisons of the association number of NMA in various solvents indicate that the degree of association is in the following order: $\mathrm{CCl}_{4} \gg$ chloroform $\fallingdotseq$ dichloromethane $>$ acetonitrile. Interestingly, the association number of $\mathrm{NMA}$ in $\mathrm{CCl}_{4}$ is thought to be larger than that in its pure liquid.
\end{abstract}

\section{Introduction}

Near-infrared (NIR) spectroscopy is a useful analytical method for practical materials [1] and has been applied to various industrial and agricultural problems $[2,3]$. The applications, however, have been mostly based on mathematical treatments of the NIR spectra but not on analytical knowledge which the NIR spectra should give. Its applicants to basic chemical problems are still very limited probably because detailed spectral analyses of standard compounds have not been well carried out. On the other hand, NIR spectroscopy has such important technical merits that a liquid quartz cell with the path length of $10 \mathrm{~mm}$ or more can be used, remote spectroscopy is applicable, and so on. The use of the long-path-length cell makes us able to obtain the more reliable results especially in concentration. To make full use of the advantages, it is absolutely important to utilize the analytical information which NIR absorptions possess.

By the way, hydrogen-bonding interactions are now known to be important in determining the structural properties of proteins. In particular, hydrogen bonding between the carboxyl oxygen and amide hydrogen atoms in the protein backbone help to stabilize the $\beta$-sheet and other motifs [4]. Among the forces that contribute to the stabilization of configuration of protein molecules in solution, intramolecular hydrogen bonds have often been assigned a key role. Furthermore, hydrogen bonding between peptide groups has indeed been definitely demonstrated in proteins and polypeptides, as well as in model amino acids and small peptides, in the solid state. Hydrogen-bonding interactions play an essential role in protein-ligand interactions and in the mechanism of peptide- and protein-mediated reactions [5-7].

One of the simple protein model peptide system is $\mathrm{N}$-methylacetamide (NMA). Therefore, NMA has been extensively studied by a variety of experimental and theoretical methods [8-19]. However, uncertainties still exist concerning the effect of hydrogen bonding on its structure and conformation. In the present study, we measured the NIR spectroscopy of NMA in various solvents such as $\mathrm{CCl}_{4}$, $\mathrm{CHCl}_{3}, \mathrm{CH}_{2} \mathrm{Cl}_{2}$, and $\mathrm{CH}_{3} \mathrm{CN}$ and calculated the aggregation number by assuming a successive association processes for NMA molecules.

\section{Experimental}

2.1. Materials. The sample of $N$-methylacetamide (NMA, its purity greater than $99.8 \%$, Tokyo Kasei Kougyou Co. Ltd.) was used after distillation. Sample of NMA- $d_{1}$ was synthesized by using the deuterium-proton exchange reaction, by stirring the NMA sample in a large excess amount 


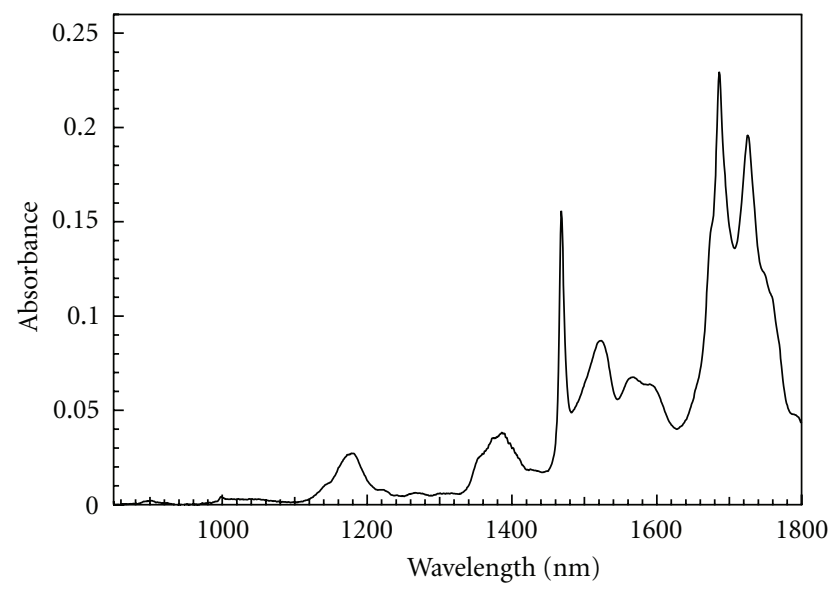

Figure 1: NIR spectrum of NMA in $\mathrm{CCl}_{4}\left(0.8 \mathrm{~mol} \mathrm{dm}^{-3}\right)$ at $30^{\circ} \mathrm{C}$.

of $\mathrm{CH}_{3} \mathrm{OD}$ (ten times amount to the NMA sample) at $40^{\circ} \mathrm{C}$, and then by the distillation of the alcohol. This deuterium-proton exchange process was repeated 7 times. Its deuterium content was determined to be $98 \%$ by NIR spectroscopic observation. Carbon-disulfide-free sample of carbon tetrachloride $\left(\mathrm{CCl}_{4}\right.$, its purity greater than $99.5 \%$, Nakaraitesk Co. Ltd.) was dried by 7 hrs refluxing over $\mathrm{P}_{2} \mathrm{O}_{5}$ and distillated under an atmosphere of dried nitrogen. The samples of dichloromethane and chloroform $\left(\mathrm{CH}_{2} \mathrm{Cl}_{2}\right.$ and $\mathrm{CHCl}_{3}$, their purities greater than 99\%, Wako Junyaku Kogyo Co. Ltd.) were used after distillation also under nitrogen gas atmosphere. The sample of acetonitrile $\left(\mathrm{CH}_{3} \mathrm{CN}\right.$, its purity greater than 99.9\%, Wako Junyaku Kogyo Co. Ltd.) was used without further purification.

2.2. Near-Infrared Spectropic Measurement. The NIR spectra were measured at a resolution of $1.0 \mathrm{~nm}$ on a Hitachi-3500 spectrophotometer. A quartz cell having 5.0 or $10 \mathrm{~mm}$ path length was used. A Hitachi temperature-regulated cell holder (No. 131-0040) was used to maintain the temperature of the sample within $\pm 0.05^{\circ} \mathrm{C}$. Temperature control of the thermostat water was carried out with a temperature controller (Yamato-Komatsu colonics circulator model CTE 32).

2.3. Density Measurement. The densities for the samples of pure liquid and the $\mathrm{CCl}_{4}$ solution of NMA were measured on a vibration-type densimeter (Anton Paar Model DMA 58) over temperature range of $10.0-65.0 \pm 0.05^{\circ} \mathrm{C}$. Degassed pure water was used for calibrating the densimeter. The absorbances were corrected for variation in the number of molecules in the light path due to the density change with temperature.

\section{Results and Discussion}

NIR spectra of the NMA in its pure liquid and in its $\mathrm{CCl}_{4}$ solutions were measured in the $800-1800 \mathrm{~nm}$ region over a temperature range of $10-60^{\circ} \mathrm{C}$.

As an example, Figure 1 shows the NIR spectrum of NMA in $\mathrm{CCl}_{4}\left(0.8 \mathrm{~mol} \mathrm{dm}^{-3}\right)$ at $30^{\circ} \mathrm{C}$. According to $[20,21]$,

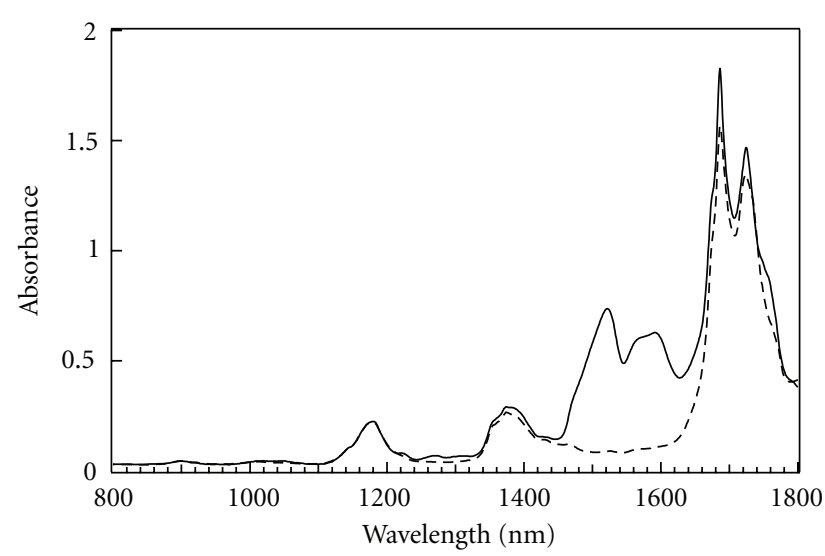

FIGURE 2: NIR spectra of samples of pure NMA (solid line) and NMA- $d_{1}$ (dashed line) at $30^{\circ} \mathrm{C}$. Comparison of the two spectra indicates that the bands of the pure sample of NMA in the 1460$1620-\mathrm{nm}$ region are only due to the vibration of $\mathrm{NH}$ group of NMA molecule.

the 1180-nm band is assigned to the second overtone of symmetric C-H stretch vibration; the 1380-nm band, to the combination bands of $\mathrm{CH}$ vibration; the strong bands near 1680 and $1720 \mathrm{~nm}$, to the first overtone of asymmetric and symmetric C-H stretch vibrations. On the other hand, the sharp 1470-nm band is thought to be attributable to the free $\mathrm{NH}$ vibration of monomer NMA; the large and broadband around $1520 \mathrm{~nm}$, to the vibration of the free, terminal $\mathrm{NH}$ moiety of hydrogen-bonded NMA aggregate [21]; and the broad 1560 and $1600-\mathrm{nm}$ bands, to the hydrogen-bonded NMA aggregates [21]. Liu et al. [22] studied precisely the dissociation of hydrogen-bonded NMA in the pure liquid state by two-dimensional Fourier-transform NIR correlation spectroscopy. They reported that the $1473-\mathrm{nm}\left(6790 \mathrm{~cm}^{-1}\right)$ band is assigned to the free $\mathrm{NH}$ group of monomer NMA; the 1504-nm $\left(6650 \mathrm{~cm}^{-1}\right)$ band, to the terminal-free (freeend) $\mathrm{NH}$ groups of the dimer; the $1536-\mathrm{nm}\left(6510 \mathrm{~cm}^{-1}\right)$ band, to the free-end $\mathrm{NH}$ group of oligomer; the 1553$\mathrm{nm}\left(6440 \mathrm{~cm}^{-1}\right)$, to the hydrogen-bonded $\mathrm{NH}$ groups of dimer or small oligomers; the $1600-\mathrm{nm}\left(6250 \mathrm{~cm}^{-1}\right)$ band, to the hydrogen-bonded $\mathrm{NH}$ groups of oligomers. In order to confirm additionally the validity of this $\mathrm{NH}$ band assignments in the $1460-1620 \mathrm{~nm}$ region, we measured the NIR spectrum of NMA- $d_{1}$ sample at $30^{\circ} \mathrm{C}$.

Figure 2 shows the NIR spectra of pure liquid NMA (solid line) and NMA- $d_{1}$ (dotted line) samples at $30^{\circ} \mathrm{C}$. The bands existing around $1460-1620 \mathrm{~nm}$ in the spectrum of the pure liquid sample of NMA apparently disappear in the spectrum of NMA- $d_{1}$. The bands due to $\mathrm{CH}$ vibrations are not observed in this region of the spectrum of NMA- $d_{1}$. This means that the bands of NMA in its pure liquid in the 1460-1620 nm region are attributable almost to the several vibrations of $\mathrm{NH}$ groups. Furthermore, in the spectrum of the pure liquid sample of NMA, the 1470-nm band due to the free NH moiety of NMA monomer is almost negligible; the two large bands are attributable to the free-end $\mathrm{NH}$ moiety of the hydrogen-bonded NMA aggregates and to the hydrogenbonded $\mathrm{NH}$ of aggregates, respectively. 


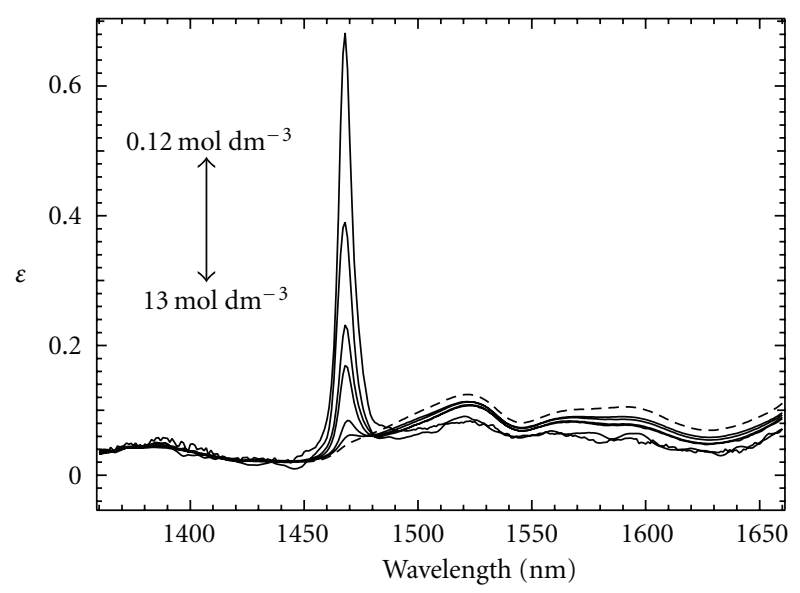

FIgURE 3: Concentration dependence of the apparent molar absorptivity $\varepsilon$ of NMA in $\mathrm{CCl}_{4}(0.12,0.25,0.6,1.0,4.0$, and $\left.8.0 \mathrm{~mol} \mathrm{dm}^{-3}\right)$ and in pure liquid $\left(13.0 \mathrm{~mol} \mathrm{dm}^{-3}\right.$; dashed line $)$ at $30^{\circ} \mathrm{C}$. The $\varepsilon$ value was obtained by dividing the observed absorbance by the light-path length of the cell and the NMA concentration. The 1470-nm band due to the free NH moiety of monomer steeply increases with decreasing concentration of NMA, while the 1520 and 1600-nm bands due to the hydrogen-bonded NMA aggregates slightly decrease. The dashed line denotes the pure liquid sample of NMA. The $\varepsilon$ of pure liquid at $1470 \mathrm{~nm}$ is very small compared with those at low concentrations.

Figure 3 represents the concentration dependence of the spectra in the $1460-1620 \mathrm{~nm}$ region of $\mathrm{NH}$ vibration of $\mathrm{NMA}$ in $\mathrm{CCl}_{4}$ solutions and in pure liquid state (dashed line) at $30^{\circ} \mathrm{C}$. In this figure, the intensity of the absorption bands for NMA is presented in terms of the apparent molar absorptivity $\varepsilon$ which was obtained by dividing the observed absorbance by the light path length of the cell and the NMA concentration. Concentrations, $C$, of NMA solutions were $0.12,0.25,0.6,1.0,4.0,8.0$, and $13.0 \mathrm{~mol} \mathrm{dm}^{-3}$ (pure liquid sample), respectively.

The apparent $\varepsilon$ of $1470-\mathrm{nm}$ band due to the $\mathrm{NH}$ vibration of NMA monomer steeply increases with a decrease in the NMA concentration; the relatively broad $1520-\mathrm{nm}$ band due to the free, terminal $\mathrm{NH}$ moiety of the hydrogen-bonded NMA aggregate slightly decreases; the broad $1550-1600 \mathrm{~nm}$ band due to the NH groups in the NMA aggregates also slightly decreases.

As denoted by the dashed line in Figure 3, the apparent molar absorptivity value, $\epsilon_{p}$, for the terminal $\mathrm{NH}$ group of the hydrogen-bonded NMA for the pure liquid was $0.0206 \mathrm{~cm}^{-1} \mathrm{~mol}^{-1} \mathrm{dm}^{3}$ at $1470 \mathrm{~nm}$.

Apparently, at low concentration, the contribution of the tail part of the terminal NH band of NMA aggregate to the free monomer NH band at $1470 \mathrm{~nm}$ is extremely small. Thus, the contribution of the tail part of the free, terminal $\mathrm{NH}$ moiety of the hydrogen-bonded NMA aggregates is almost negligible at low concentrations.

From the spectra of the pure liquid NMA and NMA$d_{1}$ samples, we have estimated that the bands due to the $\mathrm{CH}$ vibrations would not exist in the 1460-1620-nm region. However, there remains a possibility that the deuterium- hydrogen exchange of NMA is not complete. Consequently, the slight contribution of $\mathrm{CH}$ vibration may still remain in the $1460-1620 \mathrm{~nm}$ region.

Therefore, to eliminate completely the bands due to the $\mathrm{CH}$ vibrations from the $1470-\mathrm{nm}$ band due to the $\mathrm{NH}$ vibration of NMA monomer, we adopted the spectrum of the pure-liquid NMR sample as a reference at $30^{\circ} \mathrm{C}$. One reason is that, as the melting point of NMA crystal is 26$28^{\circ} \mathrm{C}$, the pure liquid sample of NMA would not have its monomers at this temperature. In fact, as shown in Figures 2 and 3, pure-liquid NMA sample does not show the 1470$\mathrm{nm}$ monomer band at $30^{\circ} \mathrm{C}$. Namely, to obtain the spectra, the spectrum of NMA in pure liquid measured at $30^{\circ} \mathrm{C}$ was subtracted from all the raw spectra after concentration and density corrections.

In the previous paper [23], to calculate the aggregation numbers of butanol in $\mathrm{CCl}_{4}$, we utilized the intensity of the free $\mathrm{OH}$ band of monomer butanol.

In the case of NMA, we used also the intensity of the free $\mathrm{NH}$ band of NMA monomer at $1470 \mathrm{~nm}$ for the calculation of the aggregation number of the NMA in $\mathrm{CCl}_{4}$.

Figures 4(a) and 4(b), for examples, show the temperature dependence of the difference spectra of the 0.12 and $0.25 \mathrm{~mol} \mathrm{dm}^{-3}$ samples of NMA in $\mathrm{CCl}_{4}$. At each constant concentration, the $1470-\mathrm{nm}$ band due to the free $\mathrm{NH}$ monomer steeply increases with increasing temperature while the broad 1600-nm band due to the hydrogen-bonded NMA aggregate slightly decreases.

Judging from the profiles of Figures 4(a) and 4(b), in the low concentration regions, the subtraction using the spectrum of NMA in pure liquid state seems to be acceptable. However, in the high concentration regions $(0.8,2.5$, and $8 \mathrm{~mol} \mathrm{dm}^{-3}$ ) as shown in Figures 4(c)-4(e), the contribution of the tail part of the band due to the free-end NH moiety of the hydrogen-bonded NMA aggregates to the 1470-nm monomer band becomes too large; we probably do the oversubtraction of the contribution of the tail part at high concentrations above $0.8 \mathrm{~mol} \mathrm{dm}^{-3}$. Thus, we evaluated the mean aggregation number of NMA in $\mathrm{CCl}_{4}$ only below $0.25 \mathrm{~mol} \mathrm{dm}^{-3}$.

In the evaluation of the mean aggregation number of NMA, it is essential to know the monomer concentration of NMA; the monomer concentration was calculated by using the apparent molar absorptivity, $\varepsilon$, and the molar absorptivity, $\epsilon_{m}$, for the $1470-\mathrm{nm}$ band due to the free $\mathrm{NH}$ group of NMA monomer.

The $\epsilon_{m}$ was obtained from the concentration $\left(C_{t}\right)$ dependence of the absorbance, $A$, at the peak position of the free $\mathrm{NH}$ band of monomer in a low-concentration region, where the NMA molecules exist predominantly as monomers.

NMA gave good straight line in the $A-C_{t}$ relationships under the condition of $C_{t}<0.008 \mathrm{~mol} \mathrm{dm}^{-3}$ at various temperatures. From the slopes of the lines, we evaluated $2.08 \pm$ $0.13 \mathrm{~cm}^{-1} \mathrm{~mol}^{-1} \mathrm{dm}^{3}$ as $\epsilon_{m}$ of free NH vibration of monomer NMA. The obtained $\epsilon_{m}$ value is almost independent of temperature. This value is good agreement with the reported data by Klotz and Franzen [24] $\left(2.0 \mathrm{~mol}^{-1} \mathrm{~cm}^{-1} \mathrm{dm}^{3}\right)$ and by Liu et al. [21] $\left(1.97 \mathrm{~mol}^{-1} \mathrm{~cm}^{-1} \mathrm{dm}^{3}\right)$ and is somewhat larger than that by Krikorian [25] $\left(1.63 \mathrm{~mol}^{-1} \mathrm{~cm}^{-1} \mathrm{dm}^{3}\right)$. 


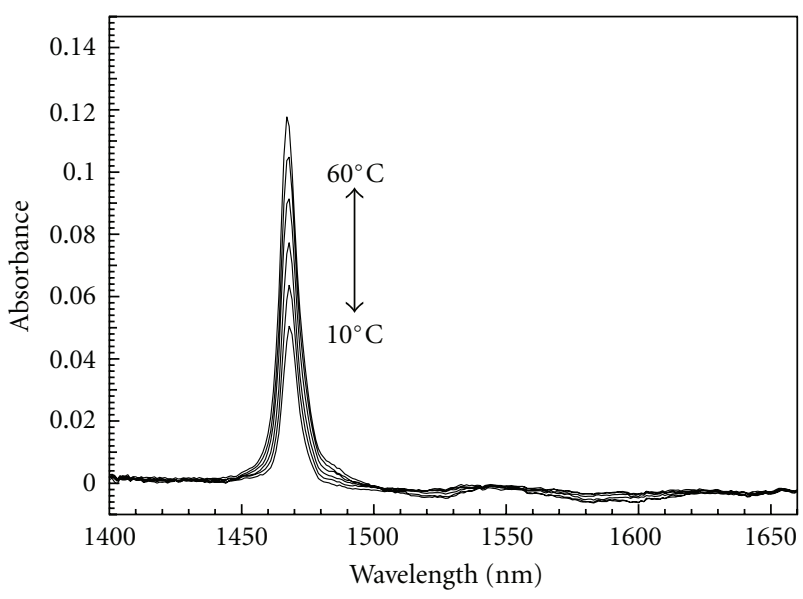

(a)

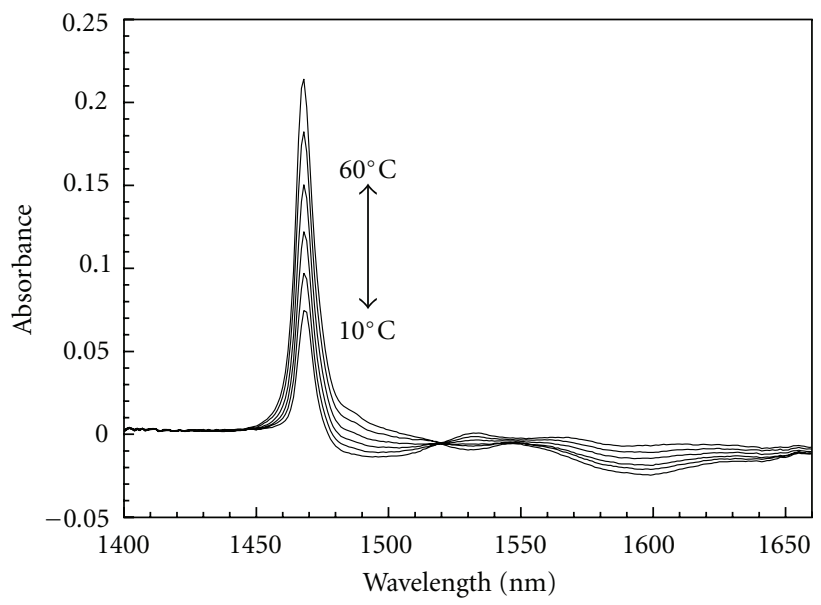

(c)

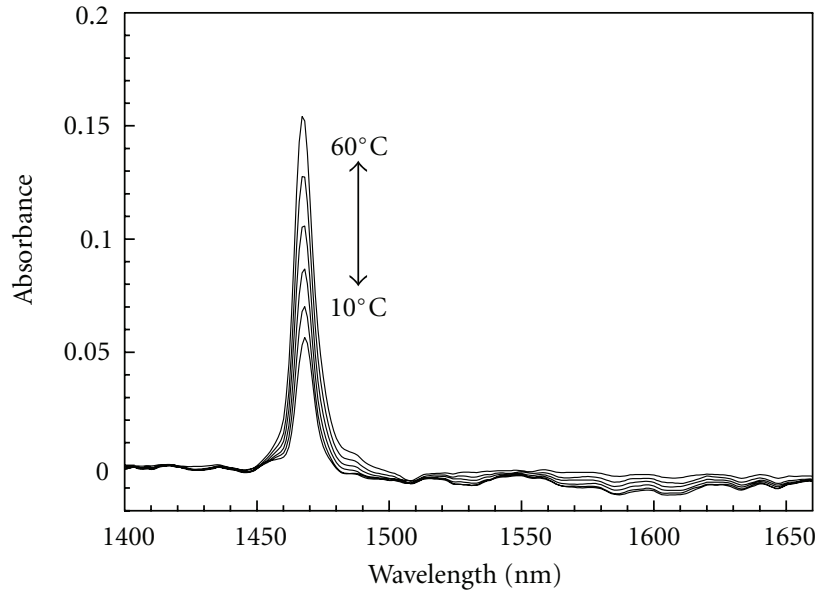

(b)

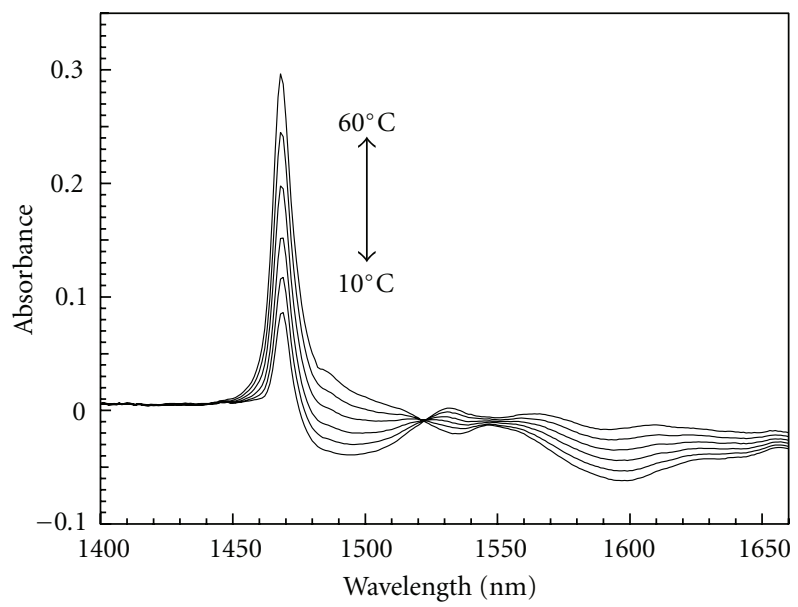

(d)

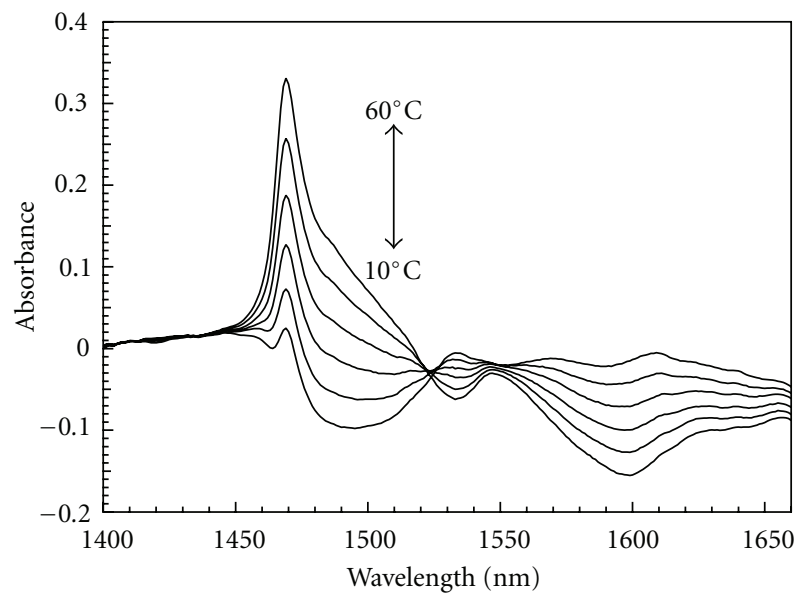

(e)

Figure 4: Temperature dependence $\left(10-60^{\circ} \mathrm{C}\right)$ of difference spectra of NMA in $\mathrm{CCl}_{4}$ ((a) $0.12 \mathrm{~mol} \mathrm{dm}^{-3}$; (b) $0.25 \mathrm{~mol} \mathrm{dm}^{-3}$; (c) $0.80 \mathrm{~mol} \mathrm{dm}^{-3}$; (d) $2.5 \mathrm{~mol} \mathrm{dm} \mathrm{m}^{-3}$; (e) $8.0 \mathrm{~mol} \mathrm{dm}^{-3}$ ). The spectrum of pure liquid sample of NMA at $30^{\circ} \mathrm{C}$ was taken as a reference. The subtraction was carried out after the concentration and density corrections of the pure NMA and $\mathrm{CCl}_{4}$ solution samples. The 1470 -nm band due to the free NH of monomer increases with increasing temperature and the 1520 -nm band due to the free, terminal NH moiety of hydrogen-bonded NMA aggregates decreases with increasing temperature. The free, terminal NH moiety of the hydrogen-bonded NMA aggregates seems to be oversubtracted below $30^{\circ} \mathrm{C}$ as shown in Figures $4(\mathrm{c}), 4(\mathrm{~d})$, and $4(\mathrm{e})$. 


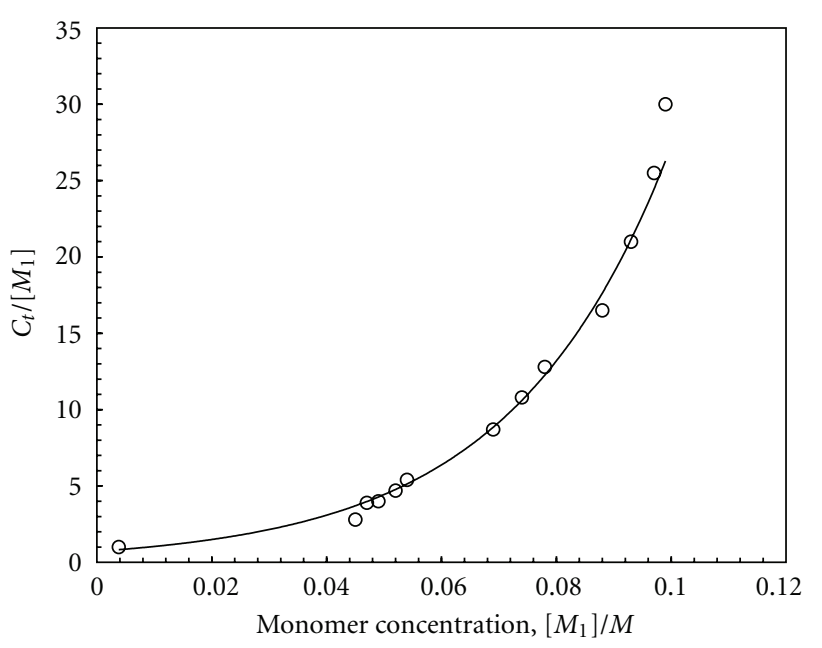

Figure 5: $C_{t} /\left[M_{1}\right]$ versus $\left[M_{1}\right]$ relationship for NMA at $20^{\circ} \mathrm{C}$.

3.1. Evaluation of the Mean Association Number. Trabelsi et al. [26] reported that the NMA molecules exist somewhat as the ring cis trimer as well as the linear trans trimer at liquid state. However, in the relatively dilute $\mathrm{CCl}_{4}$ solution, the NMA molecules would associate into large aggregates through the following successive process:

$$
\begin{array}{ll}
M_{1}+M_{1}=M_{2} ; \quad \beta_{2}=\frac{\left[M_{2}\right]}{\left[M_{1}\right]^{2}}, & \therefore\left[M_{2}\right]=\beta_{2}\left[M_{1}\right]^{2}, \\
M_{2}+M_{1}=M_{3} ; \quad \beta_{3}^{\prime}=\frac{\left[M_{2}\right]}{\left[M_{2}\right]\left[M_{1}\right]}, \quad \therefore\left[M_{3}\right]=\beta_{3}\left[M_{1}\right]^{3} .
\end{array}
$$

For $i$-mer, in general,

$$
M_{i-1}+M_{1}=M_{i} ; \quad \beta_{i}^{\prime}=\frac{\left[M_{i}\right]}{\left[M_{i-1}\right]\left[M_{1}\right]}, \quad \therefore\left[M_{i}\right]=\beta_{i}\left[M_{1}\right]^{i},
$$

where $\beta_{i}=\beta_{2} \beta_{3}^{\prime}, \ldots, \beta_{i-1}^{\prime} ; \beta_{3}^{\prime}, \beta_{4}^{\prime}, \ldots$, and $\beta_{i}^{\prime}$ are the association constants for each process, and $\beta_{2}, \beta_{3}, \ldots$, and $\beta_{i}$, the overall association constants for the formation of dimer, trimer, and $i$-mer, respectively. $\left[M_{1}\right],\left[M_{2}\right],\left[M_{3}\right], \ldots$ and $\left[M_{i}\right]$ denote the concentrations of monomer, dimer, trimer, and $i$-mer, respectively. In the equations, both types of aggregates, that is, linear and cyclic ones, are possible for the $i$-mers. In practice, however, cyclic aggregates would not be coexistent with open-linear species. This is because most NMA molecules exist in flat, transform structure; the formation of cyclic aggregates is thought to be very difficult. In addition, cyclic structures exhibit more order (less freedom), and, therefore, their formation involves greater entropy loss than for the formation of the equivalent open structures. Consequently, the main oligomer species would be linear types of species. Thus, as a first approximation we applied the simple successive aggregation process for the formation of the linear-type oligomer species.
The total concentration, $C_{t}$, can be expressed in terms of the monomer concentration, $\left[M_{1}\right]$.

$$
\begin{aligned}
C_{t} & =\left[M_{1}\right]+2\left[M_{2}\right]+3\left[M_{3}\right]+\cdots+i\left[M_{i}\right]+\cdots \\
& =\sum i\left[M_{i}\right]=\sum i \beta_{i}\left[M_{1}\right]^{i} .
\end{aligned}
$$

On the other hand, if we regard the oligomers (dimer, trimer, tetramer, and so on) as a sort of particle, the total concentration of the particles, $C_{m}$, would be represented by $(4)$

$$
\begin{aligned}
C_{m} & =\left[M_{1}\right]+\left[M_{2}\right]+\left[M_{3}\right]+\cdots+\left[M_{i}\right]+\cdots \\
& =\sum\left[M_{i}\right]=\sum \beta_{i}\left[M_{1}\right]^{i} .
\end{aligned}
$$

Differentiation of (4) with respect to $\left[M_{1}\right]$ and combination with (3) leads to(5)

$$
\frac{\mathrm{d} C_{m}}{\mathrm{~d}\left[M_{1}\right]}=\sum i \beta_{i}\left[M_{1}\right]^{i-1}=\frac{\sum i \beta_{i}\left[M_{1}\right]^{i}}{\left[M_{1}\right]}=\frac{C_{t}}{\left[M_{1}\right]} .
$$

Thus, the $C_{m}$ is represented by the integral of (5)

$$
C_{m}=\int_{\sim 0}^{\left[M_{1}\right]} \frac{C_{t}}{\left[M_{1}\right]} \mathrm{d}\left[M_{1}\right] .
$$

In practice, the $C_{m}$ can be evaluated graphically through the successive area integral of the $C_{t} /\left[M_{1}\right]$ versus $\left[M_{1}\right]$ relationship, with the use of $\left[M_{1}\right]$ at an arbitrary $C_{t}$.

Then, the mean association number, $\bar{N}$, which includes monomer species, is expressed as follows:

$$
\bar{N}=\frac{C_{t}}{C_{m}} .
$$

The value of $\left[M_{1}\right]$ necessary for evaluating the $C_{m}$ and finally $\bar{N}$ values can be estimated from the apparent molar absorptivity, $\epsilon$, and the molar absorptivity $\varepsilon_{m}$ for the free $\mathrm{NH}$ band (at $1470 \mathrm{~nm}$ ) of monomer.

As a typical example, the $C_{t} /\left[M_{1}\right]$ versus $\left[M_{1}\right]$ relationship for NMA at $30^{\circ} \mathrm{C}$ is shown in Figure 5. $C_{t} /\left[M_{1}\right]$ increases gradually and steeply with an increase in $\left[M_{1}\right]$. The graphical successive area integral of the relationship gave the $C_{m}$ at an arbitrary $\left[M_{1}\right]$ or $C_{t}$. Then, the $\bar{N}$ at the arbitrary $C_{t}$ was evaluated with (7) by using the obtained $C_{m}$ value.

The $\bar{N}$ versus $C_{t}$ relationships at various constant temperatures for NMA in $\mathrm{CCl}_{4}$ are shown in Figure 6. At a constant temperature, the $\bar{N}$ value increases with an increase in concentration. At constant concentration, the $\bar{N}$ value decreases with increasing temperature.

Similar observations were carried out for the NMA samples in $\mathrm{CH}_{2} \mathrm{Cl}_{2}, \mathrm{CHCl}_{4}$, and $\mathrm{CH}_{3} \mathrm{CN}$ solutions. In these cases, the absorptions due to the solvents themselves are included in the observed spectra. Therefore, the removal of the spectra due to the solvents from the observed spectra was carried out after the back ground and density corrections. After these calculating procedures, similar calculation as same as the case of $\mathrm{CCl}_{4}$ solution was carried out.

As an example the obtained results for the mean aggregation number $\bar{N}$ of NMA in these solvents at $20^{\circ} \mathrm{C}$ are 


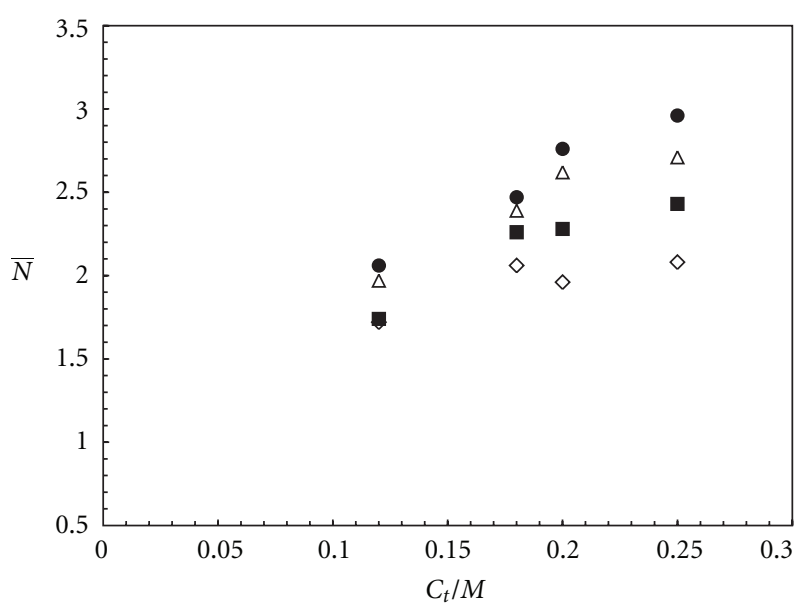

Figure 6: Mean aggregation number, $\bar{N}$, versus total concentration, $C_{t}$, of NMA at various temperatures: $\bullet$ denotes $10^{\circ} \mathrm{C} ; \triangle, 20^{\circ} \mathrm{C}$; $30^{\circ} \mathrm{C} ; \diamond, 40^{\circ} \mathrm{C}$.

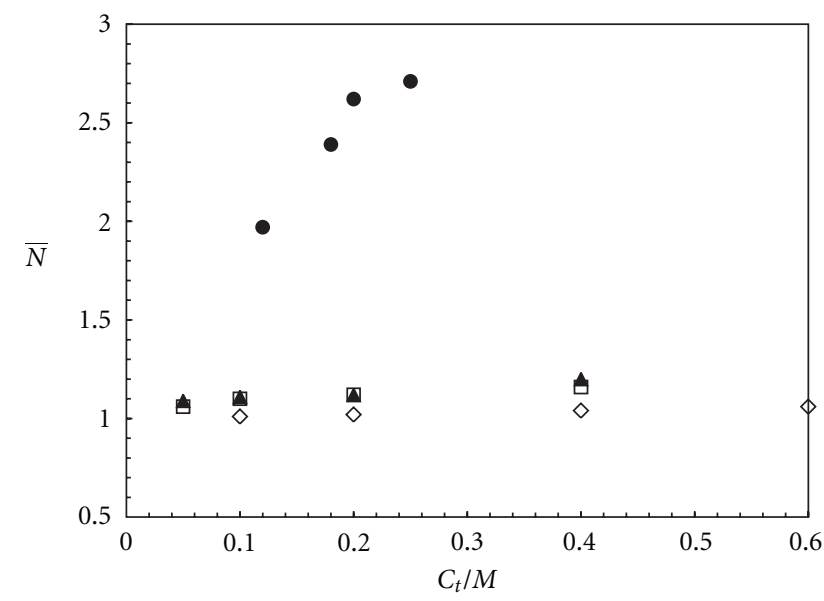

Figure 7: Mean aggregation number, $\bar{N}$, versus total concentration, $C_{t}$, of NMA in various solvents at $20^{\circ} \mathrm{C}$. $\bullet$ denotes $\mathrm{CCl}_{4} ; \mathbf{\Lambda}, \mathrm{CH}_{2} \mathrm{Cl}_{2}$; $\square, \mathrm{CHCl}_{3} ; \diamond, \mathrm{CH}_{3} \mathrm{CN}$.

plotted in Figure 7. In the case of the solvents such as $\mathrm{CH}_{2} \mathrm{Cl}_{2}$, $\mathrm{CHCl}_{4}$, and $\mathrm{CH}_{3} \mathrm{CN}$, the contributions of the free, terminal $\mathrm{NH}$ groups of the NMA aggregates to the monomer band were very small, and then the concentration regions for the calculation of aggregation number are wide, compared with the case in $\mathrm{CCl}_{4}$. The $\bar{N}$ value of NMA in $\mathrm{CH}_{3} \mathrm{CN}$ is almost 1 and very slightly increases with increasing concentration of NMA. In addition, the $\bar{N}$ values of NMA in $\mathrm{CH}_{2} \mathrm{Cl}_{2}$ and $\mathrm{CHCl}_{4}$ also slightly increase with increasing concentration of NMA but slightly larger than that in $\mathrm{CH}_{3} \mathrm{CN}$. Namely, the NMA molecules aggregate most greatly in $\mathrm{CCl}_{4}$. The dielectric constants of $\mathrm{CH}_{3} \mathrm{CN}, \mathrm{CH}_{2} \mathrm{Cl}_{2}, \mathrm{CHCl}_{4}$, and $\mathrm{CCl}_{4}$ have been reported as $37.5,9.1,4.9$, and 2.205 at $20^{\circ} \mathrm{C}$ [27], respectively. The dielectric constant of the solvents is thought to contribute the degree of association of NMA molecule.

In the low dielectric solvent such as $\mathrm{CCl}_{4}$, the NMA aggregation progresses steeply with increasing the concentration of NMA molecule.
By the way, is there a difference in the profile of the aggregates of NMA in nonpolar solvent such as $\mathrm{CCl}_{4}$ and in pure liquid? Then, we investigated effect of $\mathrm{CCl}_{4}$ on the aggregation profile of NMA.

3.2. Effect of Nonpolar Solvent on the Aggregation Profile of NMA Molecules. Figures 4(c) and 4(e) exhibit the temperature dependence of the difference spectra for $\mathrm{NMA}$ in $\mathrm{CCl}_{4}$ solution at high concentrations: $0.8,2.5$, and $8.0 \mathrm{~mol} \mathrm{dm}^{-3}$. The difference spectra were obtained by subtracting the spectrum of pure NMA sample at $30^{\circ} \mathrm{C}$ as a reference from other spectra measured at various temperatures after density correction.

Interestingly, the difference spectra below $30^{\circ} \mathrm{C}$ has a large minimum at $1510 \mathrm{~nm}$ which is very close to the band of the free, terminal $\mathrm{NH}$ of aggregate of NMA, while the $1600 \mathrm{~nm}$ band due to the hydrogen-bonded aggregates of NMA does not so decrease. This suggests that the number of terminal $\mathrm{NH}$ group decreases in $\mathrm{CCl}_{4}$ and that the aggregates become more large-sized clusters in $\mathrm{CCl}_{4}$. Namely, nonpolar solvent such as $\mathrm{CCl}_{4}$ may promote the formation of larger aggregate of NMA molecules. The solvent having low dielectric constant dislike the NMA molecules and may promote the formation of large clusters. With increasing temperature, the large cluster would dissociate more easily and then monomer band increases in its intensity. In addition, the number of the free, terminal $\mathrm{NH}$ groups of the oligomers would increase with increasing temperature. The aggregate structures in $\mathrm{CCl}_{4}$ and in liquid, however, should be clarified by more additional experiments.

\section{Conclusions}

Aggregation numbers of NMA in various solvents, such as $\mathrm{CCl}_{4}, \mathrm{CHCl}_{3}, \mathrm{CH}_{2} \mathrm{Cl}_{2}$, and $\mathrm{CH}_{3} \mathrm{CN}$, were obtained by using NIR spectroscopic observation. The order of the degree of association is $\mathrm{CCl}_{4} \gg \mathrm{CHCl}_{3} \fallingdotseq \mathrm{CH}_{2} \mathrm{Cl}_{2}>\mathrm{CH}_{3} \mathrm{CN}$. The cluster size increases with increasing NMA concentration and decreases with increasing temperature. In the solvent having a high dielectric constant, the aggregation number of NMA is very small, while in the solvent having a low dielectric constant that of NMA is very large. In addition, the nonpolar solvent such as $\mathrm{CCl}_{4}$ promotes the cluster size of NMA.

\section{Acknowledgment}

The authors are grateful to Mr. Ryo Wakasugi, Miss. Yuka Mochizuki, and Masatoshi Yokomizo for their assistances with the NIR observation.

\section{References}

[1] F. McClure, AnalyticalChemistry, vol. 43A, p. 66, 1994.

[2] P. Williams and K. Norris, Eds., Near-Infrared Technology in the Agricultural and Food Industries, AACC Press, 2nd edition, 2001.

[3] Y. Ozaki, W. F. McClure, and A. A. Christy, Eds., Near-Infrared Spectroscopy in Food Science and Technology, John Wiley \& Sons, 2006. 
[4] G. E. Schulz and R. G. Schirmer, Principles of Protein Structure, Springer, New York, NY, USA, 1998.

[5] I. D. Kuntz and W. Kauzmann, "Hydration of proteins and polypeptides," Advances in Protein Chemistry, vol. 28, pp. 239 345, 1974.

[6] L. Packer, Methods in Enzymology, vol. 127, pp. 1-416, 1986.

[7] M. Kitano, T. Fukuyama, and K. Kuchitsu, Bulletin of the Chemical Society of Japan, vol. 46, p. 384, 1973.

[8] R. J. Albers, A. B. Swanson, and G. C. Kresheck, "An equilibrium centrifugation study of the self-association of $\mathrm{N}$ methylacetamide in carbon tetrachloride solutions at 25०," Journal of the American Chemical Society, vol. 93, no. 25, pp. 7075-7078, 1971.

[9] H. Guo and M. Karplus, "Ab initio studies of hydrogen bonding of N-methylacetamide: structure, cooperativity, and internal rotational barriers," Journal of Physical Chemistry, vol. 96, no. 18, pp. 7273-7287, 1992.

[10] R. Ludwig, O. Reis, R. Winter, F. Weinhold, and T. C. Farrar, "Quantum cluster equilibrium theory of liquids: temperature dependence of hydrogen bonding in liquid Nmethylacetamide studied by IR spectra," Journal of Physical Chemistry B, vol. 102, no. 46, pp. 9312-9318, 1998.

[11] D. G. Regan, B. E. Chapman, and P. W. Kuchel, "PGSE NMR diffusion study of the self-association of N-methylacetamide in carbon tetrachloride," Magnetic Resonance in Chemistry, vol. 40, pp. S115-S121, 2002.

[12] S. Trabelsi and S. Nasr, "Intermolecular association in liquid $\mathrm{N}$-methylacetamide as studied by x-ray scattering," Journal of Chemical Physics, vol. 121, no. 13, pp. 6380-6385, 2004.

[13] M. A. Czarnecki and K. Z. Haufa, "Effect of temperature and concentration on the structure of N-methylacetamidewater complexes: near-infrared spectroscopic study," Journal of Physical Chemistry A, vol. 109, no. 6, pp. 1015-1021, 2005.

[14] K. Kwac and M. Cho, "Hydrogen bonding dynamics and twodimensional vibrational spectroscopy: N-methylacetamide in liquid methanol," Journal of Raman Spectroscopy, vol. 36, no. 4, pp. 326-336, 2005.

[15] S. Trabelsi, M. Bahri, and S. Nasr, "X-ray scattering and density-functional theory calculations to study the presence of hydrogen-bonded clusters in liquid N-methylacetamide," Journal of Chemical Physics, vol. 122, no. 2, Article ID 024502, pp. 1-8, 2005.

[16] T. W. Whitfield, G. J. Martyna, S. Allison, S. P. Bates, H. Vass, and J. Crain, "Structure and hydrogen bonding in neat $\mathrm{N}$-methylacetamide: classical molecular dynamics and raman spectroscopy studies of a liquid of peptidic fragments," Journal of Physical Chemistry B, vol. 110, no. 8, pp. 3624-3637, 2006.

[17] S. Trabelsi, S. Nasr, M. Bahri, and M. C. BellissentFunel, "Molecular association in deuterated liquid $\mathrm{N}$ methylacetamide-water complex: neutron diffraction and density functional theory study," Journal of Molecular Structure, vol. 842, no. 1-3, pp. 93-99, 2007.

[18] L. Piatkowski and H. J. Bakker, "Vibrational relaxation pathways of AI and AII modes in N-methylacetamide clusters," Journal of Physical Chemistry A, vol. 114, no. 43, pp. 1146211470, 2010.

[19] S. K. Pattanayak, N. Prashar, and S. Chowdhuri, "Effect of temperature and pressure on the structure, dynamics, and hydrogen bond properties of liquid N-methylacetamide: a molecular dynamics study," Journal of Chemical Physics, vol. 134, no. 15, article 54506, 2011.
[20] S. E. Krikorian and M. Mahpour, "The identification and origin of N-H overtone and combination bands in the nearinfrared spectra of simple primary and secondary amides," Spectrochimica Acta Part A, vol. 29, no. 7, pp. 1233-1246, 1973.

[21] Y. Liu, N. A. Czarnecki, and Y. Ozaki, Applied Spectroscopy, vol. 48, p. 1095, 1994.

[22] Y. Liu, Y. Ozaki, and I. Noda, "Two-dimensional Fouriertransform near-infrared correlation spectroscopy study of dissociation of hydrogen-bonded N-methylacetamide in the pure liquid state," Journal of Physical Chemistry, vol. 100, no. 18, pp. 7326-7332, 1996.

[23] M. Iwahashi, M. Suzuki, N. Katayama et al., "Molecular selfassembling of butan-1-ol, butan-2-ol, and 2-methylpropan2-ol in carbon tetrachloride solutions as observed by nearinfrared spectroscopic measurements," Applied Spectroscopy, vol. 54, no. 2, pp. 268-276, 2000.

[24] I. M. Klotz and J. S. Franzen, "Hydrogen bonds between model peptide groups in solution," Journal of the American Chemical Society, vol. 84, no. 18, pp. 3461-3466, 1962.

[25] S. E. Krikorian, "Determination of dimerization constants of cis- and trans-configured secondary amides using nearinfrared spectrometry," Journal of Physical Chemistry, vol. 86, no. 10, pp. 1875-1881, 1982.

[26] S. Trabelsi, S. Nasr, M. Bahri, and M. C. Bellissent-Funel, "Local order in fully deuterated liquid N-methylacetamide (C 3D7NO) as studied by neutron diffraction and densityfunctional theory calculations," Journal of Physical Chemistry B, vol. 110, no. 49, pp. 25021-25025, 2006.

[27] J. A. Riddick and W. B. Bunger, Organic Solvents, John Wiley \& Sons, 1970. 


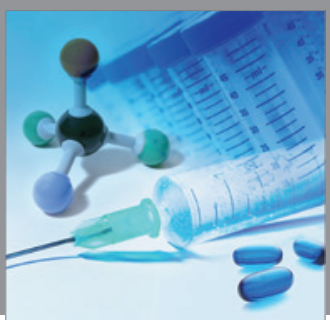

International Journal of

Medicinal Chemistry

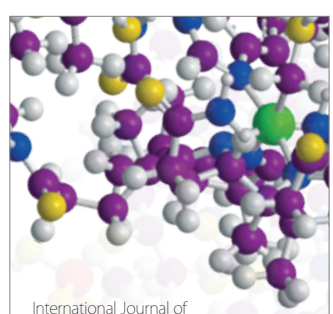

Carbohydrate Chemistry

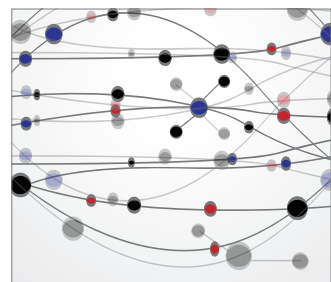

The Scientific World Journal
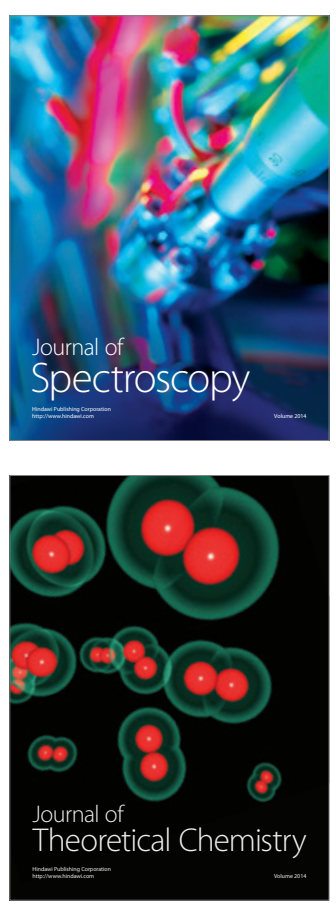
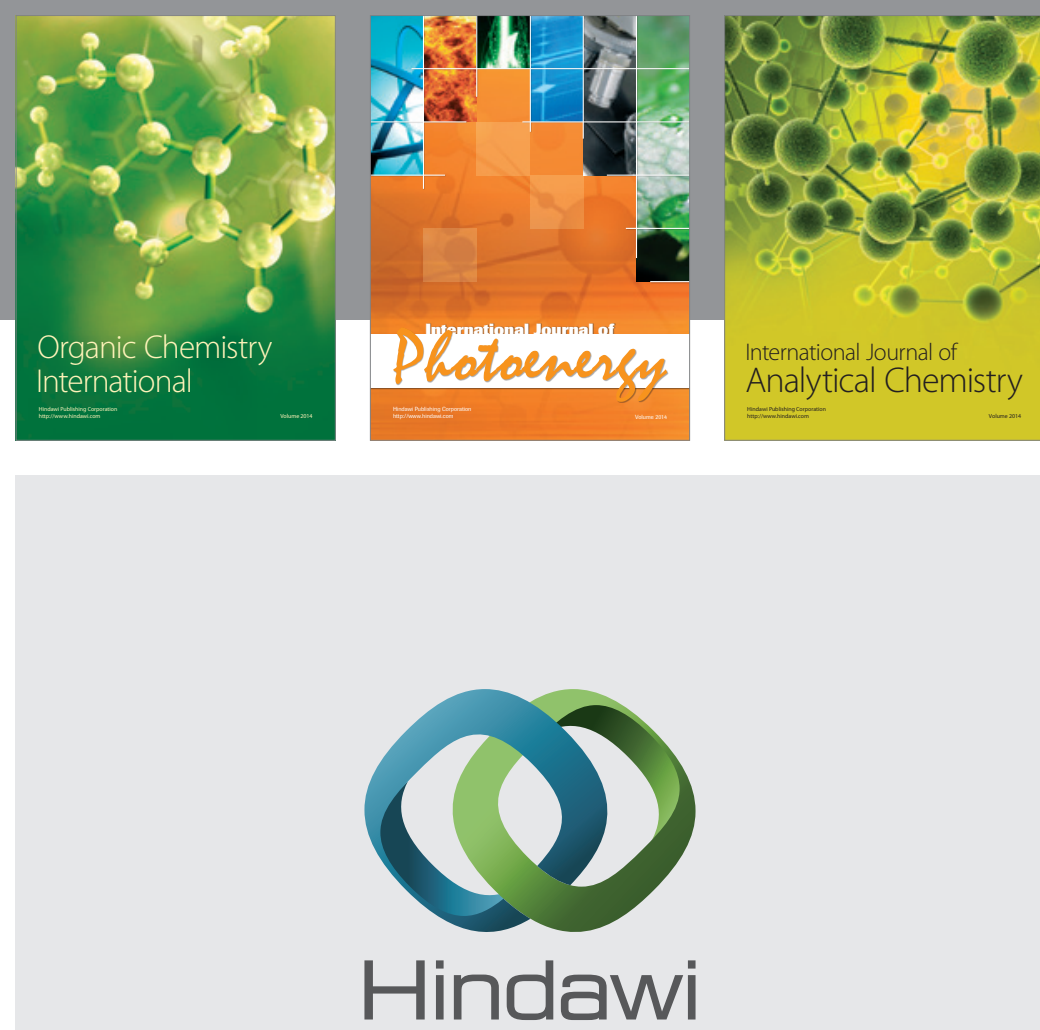

Submit your manuscripts at

http://www.hindawi.com
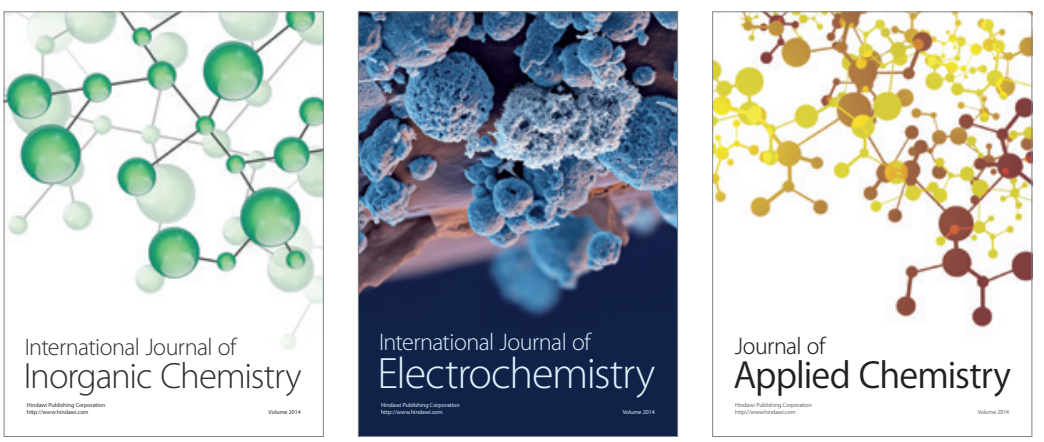

Journal of

Applied Chemistry
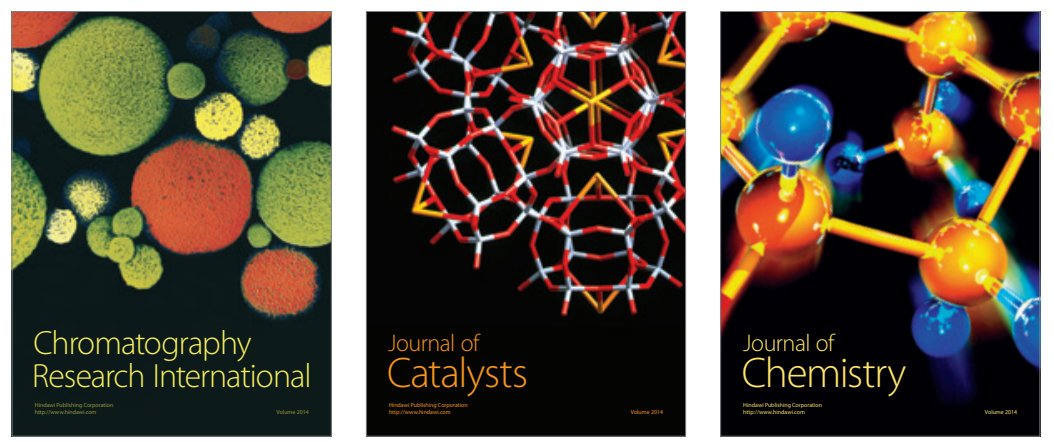
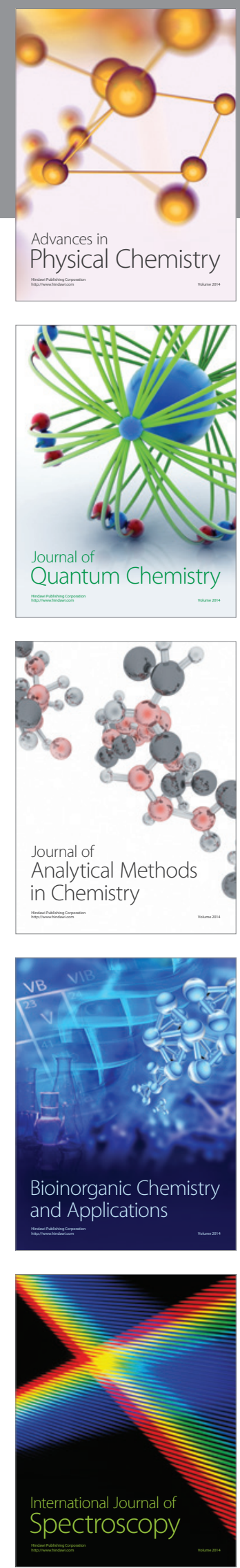